\title{
Reconstruction of Pharyngeal Defects with a Submental Island Flap after Hypopharyngeal Carcinoma Ablation
}

\author{
Wen-Hung Wang ${ }^{\text {a-c, e }}$ Tzer-Zen Hwang ${ }^{d}$ Chia-Hao Chang ${ }^{a}$ Yen-Chun Lin ${ }^{e, f}$ \\ ${ }^{a}$ Department of Otolaryngology, Cathay General Hospital, Taipei, ${ }^{b}$ Department of Otolaryngology, Sijhih \\ Cathay General Hospital, and ' $F u-J e n$ Catholic University School of Medicine, New Taipei City, ${ }^{d}$ Department of

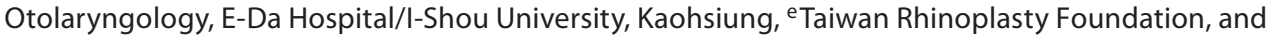 \\ $f_{i N o s e}$ Aesthetic Clinic, Taipei, Taiwan, ROC
}

\section{Key Words}

Submental island flap $\cdot$ Reconstruction $\cdot$ Hypopharyngeal cancer $\cdot$ Pharyngeal defect

\begin{abstract}
Purpose: This study aimed to evaluate the oncologic and functional results of pharyngeal defect reconstruction using a submental island flap in hypopharyngeal cancer patients. Methods: Functional and oncologic results were assessed in 14 patients based on a retrospective chart review. Speech function grading was as follows: $1=$ excellent $(>70 \%$ intelligibility); $2=\operatorname{good}(40-70 \%$ intelligibility), and $3=\operatorname{poor}(<40 \%$ intelligibility). Swallowing function score was stratified as 1 = full diet (excellent), 2 = soft diet (excellent-good), 3 = liquid diet (good), 4 = combined oral and gastric tube (goodpoor), and 5 = gastric tube-dependent (poor). Results: All flaps survived well. Salivary fistula with infection was found in 1 patient and treated conservatively. The mean length of hospitalization, and speech and swallowing scores according to laryngeal invasion in 11 patients after partial pharyngectomy were $21.63 \pm 4.31$ versus $11 \pm 2.00(p=0.003), 2.38$ \pm 0.5 versus $1.67 \pm 1.16(p=0.18)$ and $3.88 \pm 0.84$ versus $3.33 \pm 1.53(p=0.46)$, respectively. Speech and swallowing returned to good-excellent in $63.6 \%$ and good in $45.5 \%$ of
\end{abstract}

patients after surgery. Conclusions: The submental island flap is reliable for reconstructing laryngopharyngeal defects after ablation of hypopharyngeal cancer. Speech and swallowing are restored to good function in half of the patients. Laryngeal involvement of the cancer is predictive of longer hospitalization.

Copyright $\odot 2012$ S. Karger AG, Basel

\section{Introduction}

Hypopharyngeal squamous cell carcinoma is an aggressive cancer that is generally diagnosed at advanced stages. Combined-modality therapy is required in order to achieve cure, and conventional treatment for advanced but resectable cases is surgery followed by postoperative adjuvant therapy. The 5 -year survival rates vary from 10 to $60 \%$ [1-3]. However, the need for extensive ablative surgery, often coupled with radiotherapy, renders many patients incapable of performing basic human functions like swallowing and speech, leading to negative effects on their quality of life [4]. It is imperative to use a reliable reconstructive strategy with low morbidity that will expedite the restoration of speech and swallowing. Thus, the reconstructive technique for pharyngeal defects should be

\section{KARGER}

Fax +4161306 1234

E-Mail karger@karger.ch

www.karger.com (c) 2012 S. Karger AG, Basel

0301-1569/12/0746-0304\$38.00/0

Accessible online at:

www.karger.com/orl
Wen-Hung Wang, MD, PhD, FACS

Department of Otolaryngology-Head and Neck Surgery

Chang Gung Memorial Hospital at Chiayi and College of Medicine

Chang Gung University, 6 West Sec, Chia-Pu Road

Pu-Tzu City, Chiayi County 613, Taiwan (ROC), E-Mail ent.taiwan@gmail.com 
Table 1. Demographic features of patients (all male) with hypopharyngeal carcinoma (CA) after surgery and reconstruction with a submental island flap $(\mathrm{n}=14)$

\begin{tabular}{|c|c|c|c|c|c|c|c|c|c|c|}
\hline No. & $\begin{array}{l}\text { Age } \\
\text { years }\end{array}$ & $\begin{array}{l}\text { Primary } \\
\text { site }\end{array}$ & TNM (stage) & $\begin{array}{l}\text { Flap size } \\
\text { (defect size), } \mathrm{cm}\end{array}$ & $\begin{array}{l}\text { Hospi- } \\
\text { talization } \\
\text { days }\end{array}$ & $\begin{array}{l}\text { Speech } \\
\text { score }\end{array}$ & $\begin{array}{l}\text { Swallowing } \\
\text { score }\end{array}$ & $\begin{array}{l}\text { Adjuvant } \\
\text { therapy }\end{array}$ & Morbidity and second primary cancer & $\begin{array}{l}\text { Out- } \\
\text { come }\end{array}$ \\
\hline 2 & 46 & PW & T2N2bM0 (IVa) & $6.5 \times 3.5(6 \times 3)$ & 13 & 1 & 3 & CRT & esophageal CA, tonsillar CA & alive \\
\hline 3 & 76 & PS & T4aN0M0 (IVa) & $7 \times 4(6 \times 3)$ & 47 & $-^{\mathrm{a}}$ & $-^{\mathrm{a}}$ & - & acute liver failure (2 months postop.) & dead \\
\hline 4 & 61 & PS & T2N2cM0 (IVa) & $7 \times 4(6 \times 3.5)$ & 16 & $-^{\mathrm{a}}$ & $-^{\mathrm{a}}$ & CRT & & alive \\
\hline 7 & 38 & PS & T2N2bM0 (IVa) & $7 \times 4(6.5 \times 3)$ & 23 & 3 & 3 & RT & floor of mouth CA & alive \\
\hline 8 & 45 & PS & T4N2bM0 (IVa) & $9 \times 5(7.5 \times 4)$ & 24 & 2 & 3 & RT & tongue $\mathrm{CA}$ & alive \\
\hline 9 & 61 & PS & T2N1M0 (III) & $9 \times 4.5(7 \times 3.5)$ & 22 & 2 & 4 & CRT & esophageal CA & dead \\
\hline 10 & 53 & PS & T4aN2M0 (IVa) & $10.5 \times 5(9 \times 4.5)$ & 25 & $-^{\mathrm{a}}$ & $-^{\mathrm{a}}$ & CRT & salivary fistula and infection, buccal CA & dead \\
\hline 11 & 42 & PS & T2N0M0 (II) & $4 \times 3(3 \times 2.5)$ & 15 & 2 & 4 & RT & soft palatal CA & alive \\
\hline
\end{tabular}

PS = Pyriform sinus; $\mathrm{PW}=$ pharyngeal wall; $\mathrm{CRT}$ = chemoradiotherapy; $\mathrm{RT}$ = radiotherapy; $\mathrm{CA}$ = cancer; postop. = postoperative.

a Three patients who received total larygopharyngectomy were excluded for speech and swallowing analysis.

in one stage, generate low morbidity, and allow for the rapid restoration of functions. However, even though several reconstruction methods have been proposed, from primary closure to distant tissue transfer, the choice often depends on the surgeon's training and preference.

The submental island artery flap has become increasingly popular since its introduction by Martin et al. [5] in 1993. The earliest report on the use of this flap for reconstruction in oral carcinoma was by Sterne and Hall [6] in 1996. Thereafter, the flap has been extensively used for reconstruction of oral cavity soft tissue defects, including the tongue, floor of the mouth, buccal mucosa, palate and external face [7-11].

To date, there is still no report in the English literature regarding the use of the submental island flap for pharyngeal defect reconstruction in patients with hypopharyngeal cancer. This study presents a preliminary experience and evaluates the reliability and speech/swallowing functional outcome of this flap.

\section{Materials and Methods}

The medical records of 14 patients with hypopharyngeal cancer who were surgically treated (total laryngopharyngectomy in 3 and partial laryngopharyngectomy in 11 , all combined with uni- lateral or bilateral neck dissection) and reconstructed with submental island flaps in a tertiary hospital between June 2004 and June 2006 were retrospectively reviewed. All were males, with mean age of $54.3 \pm 13.8$ years (range: $38-84$ years). Primary tumor size was T2 in 8 patients, T3 in 3 and T4 in 3 . The primary tumor site was from the pyriform sinus in 11 and the pharyngeal wall in 3 . The submental flap size ranged from $13 \times 5.5 \mathrm{~cm}$ to 4 $\times 3 \mathrm{~cm}$. After surgery, all patients received radiotherapy or combined chemotherapy except for 1 patient who died of acute liver failure. The mean follow-up duration was $49.6 \pm 21.3$ months (range: 2-84 months).

Demographic information and tumor-related data, including primary site and tumor stage, complications and outcome were obtained (table 1). Tumor staging was performed according to the American Joint Committee on Cancer 2007 criteria [12]. The length of hospital stay was calculated from the time of surgery to hospital discharge. The length of follow-up was measured in each patient from the time of surgery to the last documented follow-up or date of death.

The hospital's ethics committee approved the study protocol and all of the patients provided written informed consent before the surgical intervention.

\section{Surgical Techniques}

The patient was positioned supine with the head extended. An elliptical skin paddle was marked according to the size of the defect and could be extended from one angle of the mandible to the other. An upper incision was made $1.5 \mathrm{~cm}$ below the mandible in the midline. The upper border of the flap was just under the mandibular arch and the lower limit was marked by a pinch test for primary closure. The skin paddle was also designed to accommo- 

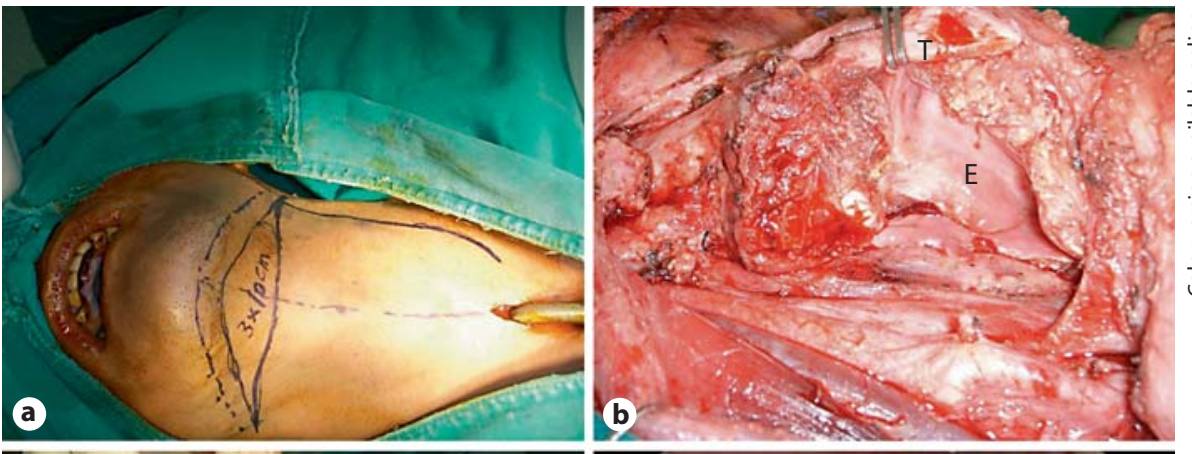

Fig. 1. a-d A 61-year-old male patient (case 9) with left hypopharyngeal cancer, T2N1M0 stage III who underwent vertical partial laryngopharyngectomy and submental island flap $(\mathrm{F})$ reconstruction. $\mathrm{E}=$ Epiglottis; $\mathrm{T}=$ thyroid cartilage.
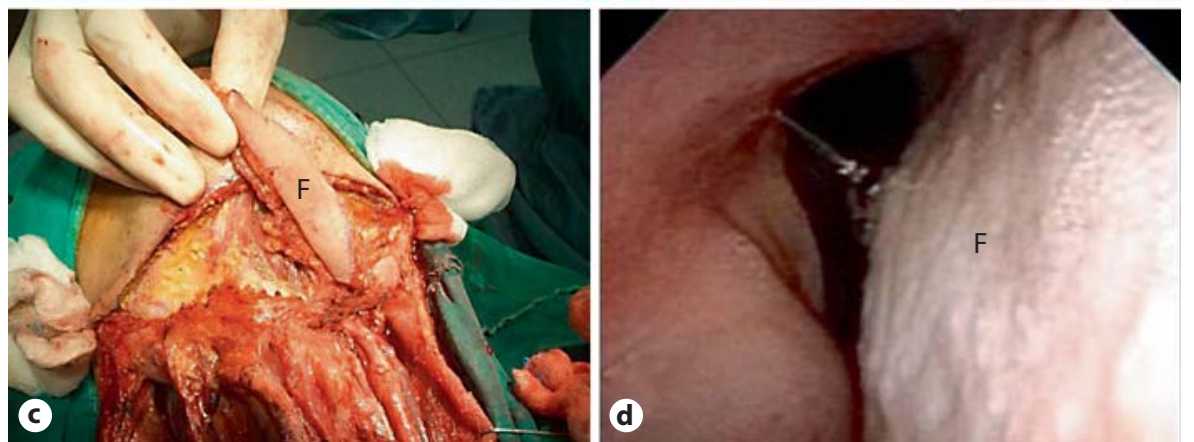

date unilateral or bilateral neck dissection. Neck dissection was first started, with extreme caution to preserve the facial vessels. The strategy regarding neck treatment was individualized for every patient but was consistent with previous reports in the literature [13]. Therefore, the N0 patients were treated by unilateral modified radical neck dissection and the N1/N2 patients underwent bilateral radical neck dissection.

Total or partial laryngopharyngectomy was performed according to the extent of tumor invasion. After completion of the tumor ablation and neck dissection, flap harvesting was started. The pharyngeal defect was measured for flap size design. The contralateral side of the flap was raised as far as the midline in the subplatysmal plane. Then the ipsilateral upper incision from the angle of the mandible to the midportion of the jaw line was taken and the dissection plane was subplatysmal. The ipsilateral anterior belly of the digastric was also included in the flap. Medial to this, the skin incision was deepened to the bone and the plane of dissection was subperiosteal so that the submental vessels lying deep in the soft tissue below the mandible were carefully included in the flap.

The reach of the flap was checked and adequate arc of rotation without tension was confirmed. The flap was then inset into the pharyngeal defect after meticulous hemostasis. The definition of ipsilateral side (proximal part) of the flap referred to the same side as the pharyngeal defect, and the contralateral side (distal part) of the flap referred to the opposite side of the defect. The proximal part of the flap was put towards the head and the suture towards the upper portion of the mucosal defect first, then gradually stitched down to the lower portion of the defect with the middle and distal part of the flap together. The cutaneous surface of the flap would become the pharyngeal side of the defect. When using a submental flap to reconstruct a total pharyngectomy de- fect, we closed the defect by the same technique as above, separated the trachea from the laryngeal box, and created a new permanent stoma. The donor site was then closed primarily in layers (fig. 1).

Speech and Swallowing Functional Outcome Assessment

Speech and swallowing functional outcome was evaluated in 11 patients who underwent partial pharyngectomy.

Standardized sentences for speech intelligibility measurement were recorded to assess speech function after surgery. Speech function was graded as follows: $1=$ excellent $(>70 \%$ intelligibility); $2=\operatorname{good}(40-70 \%$ intelligibility), and $3=$ poor $(<40 \%$ intelligibility). Grading of speech was based on observations made on the most recent office visits.

Office notes were reviewed to assess swallowing function after surgery. Swallowing function score was stratified as $1=$ full diet (excellent), 2 = soft diet (excellent-good), 3 = liquid diet (good), $4=$ combined oral and gastric tube (good-poor), and $5=$ gastric tube-dependent (poor) [14].

\section{Statistical Analyses}

Results of the current study were presented as means \pm SDs for continuous variables and as percentages for categorical variables. Statistical differences were compared using the $\chi^{2}$ test for dichotomous variables. $\mathrm{p}<0.05$ indicated statistical significance for nonparametric data analyzed by a single-tailed test. Length of hospital stay and speech and swallowing functions were tabulated and compared in terms of laryngeal invasion with appropriate statistical tests ( $\chi^{2}$ and Fisher's exact tests). All statistical analyses were performed using the SPSS version 16 (SPSS Inc., Chicago, Ill., USA). Derived confidence intervals indicated the range of values likely to reflect true significance. 


\section{Results}

\section{Oncologic Results}

All flaps survived well. Salivary fistula with infection (7.14\%) was the only major postoperative complication and was treated conservatively. The average length of hospitalization was 20.6 days (range: 9-45 days). The mean length of follow-up was 49.5 months (range: 2-84 months). There was no local recurrence. There was a neck recurrence in 1 patient $(7.14 \%)$ while 8 patients presented with a metachronous second primary site in the head and neck region (57.1\%), the most common of which was esophageal cancer. Postoperative adjuvant radiotherapy or combined chemotherapy was performed in all patients except in 1 who died of acute liver failure 2 months after surgery.

Five patients died in the 5-year postoperative followup period: 3 due to second primary site tumors, 1 due to neck recurrence, and 1 from liver disease. The actuarial 5-year survival rate was $64.3 \%$ (table 1).

\section{Functional Results}

All patients were decannulated. The average time until decannulation was 14 days (range: 5-40 days). The average time until the removal of the nasogastric tube was 35 days except in 3 patients diagnosed with a neck recurrence in 1 and esophageal cancer in 2 .

Further evaluation of the functional results in $11 \mathrm{pa}-$ tients after partial pharyngectomy regarding laryngeal (i.e. aryepiglottic fold or false cord) invasion revealed that the mean length of hospitalization was significantly longer in patients with laryngeal invasion than in those without $(21.63 \pm 4.31$ days vs. $11 \pm 2.00$ days, $p=0.003$, 95\% CI 4.63-16.62). Speech functional grading was worse in those with positive laryngeal invasion but the difference is not statistically significant $(2.38 \pm 0.5$ vs. $1.67 \pm$ $1.16, \mathrm{p}=0.18,95 \% \mathrm{CI}-0.38$ to 1.80$)$. The swallowing score did not differ between those with laryngeal invasion and those without $(3.88 \pm 0.84$ vs. $3.33 \pm 1.53, \mathrm{p}=0.46,95 \%$ CI -1.04 to 2.12 ). Speech and swallowing functions returned to good-excellent (scores 1 and 2) in $63.6 \%$ and good (scores 1, 2 and 3 ) in $45.5 \%$ of patients after surgery (table 2).

\section{Discussion}

The 5-year survival rates for hypopharyngeal cancer vary from 10 to $60 \%$ [1-3]. In this series, the 5 -year survival rate was $64.3 \%$, which can be attributed to stage II

Submental Island Flap for Pharyngeal Defects
Table 2. Comparison of hospitalization days and functional results in 11 patients after partial pharyngectomy based on tumor invasion to the larynx (means \pm SDs)

\begin{tabular}{llll}
\hline $\begin{array}{l}\text { Tumor invading } \\
\text { the larynx }\end{array}$ & $\begin{array}{l}\text { Hospitaliza- } \\
\text { tion, days }\end{array}$ & $\begin{array}{l}\text { Speech } \\
\text { score }\end{array}$ & $\begin{array}{l}\text { Swallowing } \\
\text { score }\end{array}$ \\
\hline Yes & $21.63 \pm 4.31$ & $2.38 \pm 0.52$ & $3.88 \pm 0.84$ \\
No & $11 \pm 2.00$ & $1.67 \pm 1.16$ & $3.33 \pm 1.53$ \\
p value & $0.003^{*}$ & 0.18 & 0.46 \\
$95 \%$ CI & $4.63-16.62$ & $-0.38-1.80)$ & $-1.04-2.12$ \\
\hline
\end{tabular}

${ }^{*} \mathrm{p}<0.05$, significant.

in 4 patients. All patients were treated by partial or total laryngopharyngectomy combined with unilateral or bilateral neck dissection. Resection margins were assessed on frozen sections taken intraoperatively and were free of tumor in all cases. Total laryngopharyngectomy with adjuvant radiotherapy remains the most widely used treatment in cases of late-stage hypopharyngeal squamous cell carcinoma [15]. However, the resulting permanent tracheostoma with the associated loss of voice and impaired deglutition accounts for significant postoperative morbidity. Conservative surgery with suitable reconstruction should be considered for either oncologic reasons or patient factors like adequate pulmonary reserve. Nevertheless, Plouin-Gaudon et al. [16] report that successful laryngeal function preservation with local control is achieved in $80 \%$ of patients with selected pyriform sinus cancer. Data in the present study also revealed that the speech functional grading tends to be worse in patients with laryngeal involvement.

However, laryngopharyngeal reconstruction remains a challenge for the head and neck surgeon. Lefebvre [17] stressed the possibility of function preservation surgery for advanced laryngopharyngeal cancer even in selected patients with rare indications. Surgical reconstruction should be measured by the ability to reestablish the patient's ability to speak and swallow quickly. In the past 50 years, several laryngopharyngeal reconstruction methods have been developed. The myocutaneous flap, gastric pull-up, and jejunal free flap techniques are the most popular contemporary methods. Our preliminary data showed that submental flap techniques are also a convenient and low-morbidity choice for laryngopharyngeal reconstruction.

A second primary tumor was encountered in $57.1 \%$ (8 out of 14 patients) in this series in the 5 -year postopera- 
tive follow-up period, including cancers of the esophagus, tonsils, floor of the mouth, tongue, buccal mucosa and soft palate. This high rate of metachronous second primary tumors may be ascribed to the fact that all our patients presented three risk factors: smoking, betelnut use and alcoholism.

The second primary tumor was the main oncologic cause of death in our cohort. In head and neck cancers, the probability of developing a second metachronous cancer 5 years after undergoing treatment for the initial tumor is $22 \%$ and the second malignancy is almost always fatal [18]. In this series, $25 \%(2 / 8)$ of patients died of second primary tumors within the 5-year postoperative follow-up period. Thus, close screening of all subsites of the head and neck region is mandatory.

Partial laryngopharyngectomy is the most challenging issue of laryngopharyngeal reconstruction because of the glottic insufficiency resulting from the partial removal of the laryngeal sphincter $[19,20]$. Such insufficiency is responsible for the temporary or definitive speech and swallowing disorders. According to observations, the speech and swallowing functions can be restored when the tumor has not invaded the larynx and if laryngeal sphincter function is preserved. When the tumor has invaded the larynx, sphincter function should be reestablished to allow complete closure and achieve better functional outcomes.

Aspiration is well established as the main risk following conservative surgery of the hypopharynx [21] and this complication results from sacrificing the superior laryngeal nerve [22] in head and neck surgery [23]. In the current series, no patient presented with such episodes.

The hospital stay is significantly longer in patients with positive laryngeal involvement. Positive or negative laryngeal invasion does not show any difference in the swallowing score $(3.88 \pm 0.84$ vs. $3.33 \pm 1.53, \mathrm{p}=0.46$, $95 \%$ CI -1.04 to 2.12 ). The speech and swallowing functions returned to good-excellent (scores 1 and 2) in 63.6\% and good (scores 1, 2 and 3) in $45.5 \%$ of patients after surgery. Therefore, this study shows that the submental island flap is a reliable technique for reconstructing laryngopharyngeal defects after ablation of hypopharyngeal cancer.

Finally, the rationale for using this flap in this pilot study was the fact that level I lymph node metastasis of hypopharyngeal cancer is rare compared with oral cavity cancer. We did not need to perform neck dissection in this area and thus avoided the risk of submental vessel injury. In fact, there were no patients with cervical level I metastasis in our series and only 1 patient with a neck level II recurrence. It has been proposed that an ideal flap for head and neck reconstruction should possess extensive versatility, feasibility for anastomosis, be a time-saving procedure, and cause negligible donor site morbidity [24]. Because of the defect location and donor site, all in the same neck regions, the same surgical wound approach is possible (fig. 1a). This can reduce the length and area of the surgical wound, which may be crucial, especially for cancer patients with comorbidities.

There are potential disadvantages to the submental flap. The maximum pedicle area is $5.5 \times 13 \mathrm{~cm}$. For partial laryngeal or hypopharyngeal, defects, the flap area is usually sufficient and feasible for cutaneous-mucosal anastomoses in the mucosal defect region. However, for circumferential defects located in the pharyngeal muco$\mathrm{sa}$, it is not suitable to create a self-tubing flap because of the limitation of this flap width, which is usually less than $5.5 \mathrm{~cm}$. Another potential drawback of a submental flap is injury to the submental vessels, which could cause partial or total flap necrosis.

\section{Conclusion}

This is the first report in the English literature on the use of the submental island flap for reconstruction of pharyngeal defects in patients with hypopharyngeal cancer. The submental island flap is reliable in preserving human speech and swallowing function after reconstructive surgery. Laryngeal invasion of the cancer is predictive of longer hospitalization and worse speech function. About half of the patients recovered good speech and swallowing function, but $57.1 \%$ of patients developed second primary malignancies, especially esophageal cancer, which requires close follow-up. Submental island flap reconstruction should be considered for hypopharyngeal cancer patients who are able to undergo radical surgery. However, a study including a larger number of cases is still warranted to confirm this observation.

\section{Acknowledgments}

This work was supported by the Taiwan Rhinoplasty Foundation, Taipei, Taiwan, ROC.

\section{Disclosure Statement}

None. 


\section{References}

$>1$ Lee NY, O’Meara W, Chan K, et al: Concurrent chemotherapy and intensity-modulated radiotherapy for loco-regionally advanced laryngeal and hypopharyngeal cancers. Int J Radiat Oncol Biol Phys 2007;69:459-468.

$>2$ Arriagada R, Eschwege F, Cachin Y, Richard JM: The value of combining radiotherapy with surgery in the treatment of hypopharyngeal and laryngeal cancers. Cancer 1983; 51:1819-1825.

$>3$ Soo KC, Tan EH, Wee J, et al: Surgery and adjuvant radiotherapy vs. concurrent chemo-radiotherapy in stage III/IV nonmetastatic squamous cell head and neck cancer: a randomised comparison. Br J Cancer 2005;93:279-286.

4 Scharpf J, Esclamado RM: Reconstruction with radial forearm flaps after ablative surgery for hypopharyngeal cancer. Head Neck 2003;25:261-266.

$>5$ Martin D, Pascal JF, Baudet J, et al: The submental island flap: a new donor site: anatomy and clinical applications as a free or pedicled flap. Plast Reconstr Surg 1993;92:867-873.

$\checkmark 6$ Sterne GD, Januszkiewicz JS, Hall PN, Bardsley AF: The submental island flap. Br J Plast Surg.1996;49:85-89.

7 Merten SL, Jiang RP, Caminer D: The submental artery island flap for head and neck reconstruction. ANZ J Surg 2002;72:121124.

$>8$ Sebastian P, Thomas S, Varghese BT, Iype EM, Balagopal PG, Mathew PC: The submental island flap for reconstruction of intraoral defects in oral cancer patients. Oral Oncol 2008;44:1014-1018. $\checkmark 9$ Abouchadi A, Capon-Degardin N, Patenôtre P, Martinot-Duquennoy V, Pellerin P: The submental flap in facial reconstruction: advantages and limitations. J Oral Maxillofac Surg 2007;65:863-869.

10 Genden EM, Buchbinder D, Urken ML: The submental island flap for palatal reconstruction: a novel technique. J Oral Maxillofac Surg 2004;62:387-390.

$>11$ Uppin SB, Ahmad QG, Yadav P, Shetty K: Use of the submental island flap in oro-facial reconstruction - a review of 20 cases. J Plast Reconstr Aesthet Surg 2009;62:514-519.

12 Edge SB, Byrd DR, Compton CC, Fritz AG, Greene FL, Trotti A (eds): AJCC Cancer Staging Manual, ed 7. New York, Springer, 2010.

-13 Kania R, Hans S, Garcia D, Brasnu D, De Mones E, Laccourreye O: Supracricoid hemilaryngopharyngectomy in patients with invasive squamous cell carcinoma of the pyriform sinus. II. Incidence and consequences of local recurrence. Ann Otol Rhinol Laryngol 2005;114:95-104.

14 Paydarfar JA, Patel UA: Submental island pedicled flap vs radial forearm free flap for oral reconstruction: comparison of outcomes. Arch Otolaryngol Head Neck Surg 2011;137:82-87.

15 Clayman GL, Weber RS, O’Mailley BB: Cancer of the hypopharynx and the cervical esophagus; in Harrison LB, Sessions RB, Hong WK (eds): Head and Neck Cancer: A Multidisciplinary Approach. Philadelphia, Lippincott-Raven, 1999:529-554.
16 Plouin-Gaudon I, Lengelé B, Desuter G, et al: Conservation laryngeal surgery for selected pyriform sinus cancer. Eur J Surg Oncol 2004;30:1123-1130.

$\checkmark 17$ Lefebvre JL: Surgery for laryngopharygeal SCC in the era of organ preservation. Clin Exp Otorhinolaryngol 2009;2:159-163.

18 Schwartz LH, Ozsahin M, Zhang GN, et al: Synchronous and metachronous head and neck carcinomas. Cancer 1994;74:19331938.

19 Stark B, Nathanson A: The free radical forearm flap: a reliable method for reconstruction of the laryngohypopharynx after incontinuity resection. Acta Otolaryngol 1998; 118:419-422.

20 Chantrain G, Deraemaecker R: Glottic reconstruction after cricohyoidoepiglottopexy with a radial forearm free flap that includes the tendon of the palmaris longus: preliminary results and perspectives. Laryngoscope 1994;104(8 pt 1):1035-1040.

21 Yoo SJ, Lee SH, Koh KS, Kim SY: Larynx preservation surgery in pyriform sinus cancer. Int Surg 2000;85:93-98.

22 Teymoortash A, Berger R, Lichtenberger G, Werner JA: Function and dysfunction of the superior laryngeal nerve (in German). HNO 2007.

23 Finck C: Laryngeal dysfunction after thyroid surgery: diagnosis, evaluation and treatment. Acta Chir Belg 2006;106:378-387.

24 Wei FC, Jain V, Celik N, et al: Have we found an ideal soft-tissue flap? An experience with 672 anterolateral thigh flaps. Plast Reconstr Surg 2002:109:2219-2230. 